\title{
Dentists' Knowledge and Opinions of Oral-Systemic Disease Relationships: Relevance to Patient Care and Education
}

\author{
David W. Paquette, DMD, MPH, DMSc; Kathryn P. Bell, RDH, MS; Ceib Phillips, MPH, \\ PhD; Steven Offenbacher, DDS, PhD, MMSc; Rebecca S. Wilder, RDH, MS
}

Abstract: Population studies consistently support associations between poor oral (periodontal) health and systemic diseases such as cardiovascular disease (CVD) and diabetes. The aim of this study was to assess the knowledge of dentists and document their opinions regarding the evidence on oral-systemic disease relationships. A survey consisting of 39 items was developed and mailed to 1,350 licensed dentists in North Carolina. After three mailings, 667 dentists (49\%) meeting inclusion criteria responded. The respondents were predominantly male (76.3\%), in solo practice (59.5\%), and in non-rural settings (74\%). More than $75 \%$ of these dentists correctly identified risk factors like diet, genetics, smoking, obesity, and physical inactivity for CVD and diabetes. The majority rated the evidence linking periodontal disease with CVD and diabetes as strong (71\% and $67 \%$, respectively). These dentists were most comfortable inquiring about patients' tobacco habits (93\%), treating patients with diabetes (89\%) or CVD $(84 \%)$ and concurrent periodontal disease, and discussing diabetes-periodontal disease risks with patients $(88 \%)$. Fewer respondents were comfortable asking patients about alcohol consumption (54\%) or providing alcohol counseling (49\%). Most agreed that dentists should be trained to identify risk factors (96\%) or actively manage systemically diseased patients (74\%). Over $90 \%$ agreed that medical and dental professionals should be taught to practice more collaboratively. These data indicate that these dentists were knowledgeable about oral-systemic health associations, had mixed comfort levels translating the evidence into clinical practice, but expressed support for interprofessional education to improve their readiness to actively participate in their patients' overall health management.

Dr. Paquette is Professor and Associate Dean for Education, Stony Brook University School of Dental Medicine; Prof. Bell is Assistant Professor, Pacific University School of Dental Health Science; Dr. Phillips is Professor, Department of Orthodontics and Assistant Dean for Advanced Education/Graduate Programs, University of North Carolina at Chapel Hill School of Dentistry; Dr. Offenbacher is W.R. Kenan Jr. Distinguished Professor, Chair of the Department of Periodontology, and Director of the Center for Oral and Systemic Diseases, North Carolina Oral Health Institute, University of North Carolina at Chapel Hill School of Dentistry; and Prof. Wilder is Professor in the Department of Dental Ecology, Director of Graduate Dental Hygiene Education, and Director of Faculty Development, University of North Carolina at Chapel Hill School of Dentistry. Direct correspondence to Dr. David Paquette, Stony Brook University School of Dental Medicine, 150 Rockland Hall, Stony Brook, NY 11794; 631-632-3029; david.paquette@stonybrook.edu.

Keywords: dentists, dental education, dental practice, interprofessional education, oral-systemic links, periodontitis, periodontal disease, risk assessment

Submitted for publication 8/12/14; accepted 11/23/14

$I^{\prime}$ n the 2000 report Oral Health in America, the U.S. surgeon general affirmed for the first time the importance of oral health to the general health and well-being of the population. ${ }^{1}$ The surgeon general observed that there are "profound and consequential disparities in the oral health of our citizens" and that "this burden of disease restricts activities in school, work, and home, and often significantly diminishes the quality of life." The report reiterated that "general health risk factors common to many diseases, such as tobacco use and poor dietary practices, also affect oral and craniofacial health." The report highlighted that "research findings have pointed to possible associations between chronic oral infections and diabetes, heart and lung diseases, stroke, and low-birthweight, premature births."
Since the surgeon general's seminal report, a number of systematic reviews and meta-analyses have confirmed consistent, measurable associations for poor oral health (periodontal disease or periodontitis) and systemic diseases and conditions in populations. For instance, Bahekar et al. conducted a meta-analysis of five prospective cohort studies constituting approximately 86,000 subjects and concluded that individuals with periodontitis had a 1.14 times higher risk of developing coronary heart disease than control subjects without periodontitis (relative risk, $\mathrm{RR}=1.14,95 \% \mathrm{CI} 1.07-1.21) .{ }^{2}$ For five case control studies constituting 1,423 subjects, cases with periodontitis showed greater odds for developing coronary heart disease (odds ratio, $\mathrm{OR}=2.22$, 95\% CI 1.59-3.12). A meta-analysis conducted by 
Sfyroeras et al. found that the overall adjusted risk of stroke for subjects with periodontitis was 1.47 times higher in prospective studies (95\% CI 1.13-1.92) and 2.63 times higher in the reviewed retrospective studies $(95 \%$ CI $1.59-4.33)$ relative to control subjects without periodontitis. ${ }^{3}$ Borgnakke et al. conducted a systematic review and qualitative synthesis of 17 observational studies on diabetes and periodontitis and concluded that periodontal disease appears to adversely affect glycemic control, increase the likelihood of diabetic complications, and enhance the development of diabetes. ${ }^{4}$ Finally, a meta-analysis of 11 observational studies on pregnancy complications (approximately 7,600 subjects) reported an odds ratio of 2.47 (95\% CI 2.18-2.77) for preterm birth among mothers with periodontitis. ${ }^{5}$ Collectively, these systematic reviews and meta-analyses further strengthen the surgeon general's claim that oral health is an important part of general health.

In assessing the available evidence on these oral-systemic disease associations, some professional groups have published consensus reports to guide medical and dental providers in identifying patients at risk and co-managing patients with oral and systemic conditions. ${ }^{6,7}$ In addition, accrediting bodies for predoctoral dental and medical education programs have recently revised educational standards to include interprofessional interactions to foster collaborative health care teams focused on the provision of coordinated services to patients. ${ }^{8}{ }^{89}$ While a number of surveys have been published on dentists' behaviors in managing patients with diabetes mellitus, ${ }^{10-12}$ there are limited data on their knowledge and opinions on oral-systemic disease associations. Our study therefore aimed to 1) assess the knowledge of practicing dentists regarding the evidence associating periodontal disease with systemic conditions and 2) document dentists' opinions on these relationships.

\section{Methods}

To address the study aims, a survey instrument was developed, approved by the University of North Carolina at Chapel Hill Biomedical Institutional Review Board, and pilot tested. The final survey consisted of 39 items, which asked for dentists' demographics, practice characteristics, and knowledge of and opinions on several systemic health conditions (cardiovascular disease, diabetes mellitus, pregnancy complications, respiratory diseases, and others) and their relation to periodontal disease. Survey ques- tions were formulated to prompt either dichotomous or Likert-scale responses. Hard copy survey questionnaires were created using software (Teleform, Hewlett-Packard, Palo Alto, CA, USA) that allowed for scanning and electronic database entry.

A cross-sectional survey of practicing general dentists in the state of North Carolina was conducted between October 2009 and February 2010. The names and mailing addresses of 4,494 licensed general dentists in the state were obtained from the North Carolina Board of Dental Examiners. From this listing, 1,350 dentists (constituting 30\%) were randomly selected to receive surveys. Three mailings occurred in accordance with survey research best practices. ${ }^{13}$ Each mailing consisted of the survey instrument, a cover letter explaining the research project, and a stamped business return envelope. Recipients who were unwilling to participate or who were no longer in practice were instructed in the cover letter to simply return the blank survey to the investigators. To preserve confidentiality, surveys were numerically coded, and participants were asked to not enter any personal identifiable information. During the survey mailings, a research assistant maintained a linkage file with the dentists' addresses and survey numbers to track respondents and prevent duplicate mailings. Following the third mailing and prior to any scanning data entry, this linkage document was destroyed.

All data were analyzed for descriptive statistics using SAS version 9.1 (SAS Institute, Inc., Cary, NC, USA). In general, the percentage of respondents for each demographic factor, practice category, knowledge rating, and agreement strata was calculated. Bivariate chi-square testing was performed to assess whether responses for each survey item were influenced by dentists' age, practice type, or practice setting. The significance level was set at $\mathrm{p}<0.05$.

\section{Results}

A total of 667 general dentists (49\%) meeting inclusion criteria responded to the survey after the three mailings and were included in this analysis. Respondents were evenly distributed among the age categories (Table 1) but were predominantly male (76.3\%). Approximately $60 \%$ of the respondents self-identified as solo practitioners, and most reported practicing in a suburban $(38.9 \%)$ or urban setting $(35.6 \%)$ versus a rural $(25.5 \%)$ setting. The majority of these dentists $(74.6 \%)$ reported more than 30 hours of direct patient care per week in their practices. 
Table 1. Demographic and practice characteristics of North Carolina dentists participating in study $(n=667)$

\begin{tabular}{|c|c|c|}
\hline & Number & Percent \\
\hline \multicolumn{3}{|l|}{ Age in years $(n=664)$} \\
\hline$\leq 30$ & 33 & $5.0 \%$ \\
\hline $31-40$ & 150 & $22.6 \%$ \\
\hline $41-50$ & 157 & $23.6 \%$ \\
\hline $51-59$ & 189 & $28.5 \%$ \\
\hline$\geq 60$ & 135 & $20.3 \%$ \\
\hline \multicolumn{3}{|l|}{ Gender $(n=654)$} \\
\hline Male & 499 & $76.3 \%$ \\
\hline Female & 155 & $23.7 \%$ \\
\hline \multicolumn{3}{|c|}{ Primary practice type $(n=666)$} \\
\hline Group private & 222 & $33.3 \%$ \\
\hline Solo private & 396 & $59.5 \%$ \\
\hline Public health/other & 48 & $7.2 \%$ \\
\hline \multicolumn{3}{|c|}{ Primary practice setting $(\mathrm{n}=648)$} \\
\hline Urban & 231 & $35.6 \%$ \\
\hline Suburban & 252 & $38.9 \%$ \\
\hline Rural & 165 & $25.5 \%$ \\
\hline \multicolumn{3}{|c|}{ Hours/week providing patient care $(n=650)$} \\
\hline $1-10$ & 20 & $3.1 \%$ \\
\hline $11-20$ & 34 & $5.2 \%$ \\
\hline $21-30$ & 111 & $17.1 \%$ \\
\hline$>30$ & 485 & $74.6 \%$ \\
\hline
\end{tabular}

Note: Some participants skipped questions, so number of responses per item is shown in parentheses with each item. Percentages may not total $100 \%$ due to rounding.
Table 2 lists the percentage of responding dentists identifying documented risk factors for periodontitis, cardiovascular disease, diabetes mellitus, pregnancy complications (preterm birth or low birthweight delivery), and osteoporosis. A high percentage of the respondents identified poor oral hygiene $(95.8 \%)$, smoking $(94.8 \%)$, diabetes $(94.0 \%)$, oral bacteria $(89.5 \%)$, and genetics $(84.9 \%)$ as risk factors for periodontitis. For cardiovascular disease, more than $90 \%$ identified high cholesterol, smoking, high blood pressure, genetics, obesity, diet, physical inactivity, and stress as important risk factors. A majority also identified diabetes (81.9\%) and systemic inflammation $(79.0 \%)$ as risk factors for cardiovascular disease. Similarly, diet (94.0\%), obesity $(93.9 \%)$, and genetics $(87.0 \%)$ were identified as leading risk factors for diabetes mellitus, but only $60.4 \%$ cited systemic inflammation as enhancing risk for diabetes. For pregnancy complications, a high percentage of the respondents identified alcohol use $(86.8 \%)$ and smoking $(81.9 \%)$ as important risk factors. Whereas $81.6 \%$ of the responding dentists identified being postmenopausal as a risk factor for osteoporosis, only $71.1 \%$ and $40.8 \%$ cited physical inactivity or smoking, respectively, as increasing risk. These data indicate that North Carolina dentists appear more knowledgeable about the documented risk factors for cardiovascular disease, diabetes mellitus,

Table 2. North Carolina dentists' identification of risk factors for specified diseases/conditions, by percentage of total respondents $(n=667)$

Disease/Condition

\begin{tabular}{|c|c|c|c|c|c|}
\hline Risk Factor & Periodontitis & CVD & Diabetes & PTB/LBW & Osteoporosis \\
\hline Alcohol use & $67.9 \%$ & $75.1 \%$ & $64.3 \% *$ & $86.8 \%$ & $26.7 \% *$ \\
\hline Diabetes & $94.0 \%$ & $81.9 \%$ & - & $63.4 \%$ & $26.2 \%$ \\
\hline Diet & $61.8 \%$ & $92.5 \%$ & $94.0 \%$ & $59.7 \%$ & $59.5 \%$ \\
\hline Genetics & $84.9 \%$ & $93.4 \%$ & $87.0 \%$ & $48.0 \%$ & $80.4 \%$ \\
\hline High blood pressure & $30.3 \%$ & $94.0 \%$ & $48.7 \%$ & $39.9 \%$ & $9.5 \%$ \\
\hline High cholesterol & $18.3 \%$ & $94.9 \%$ & $35.8 \%$ & $15.3 \%$ & $6.0 \%$ \\
\hline Increased stress & $72.0 \%$ & $92.5 \%$ & $57.6 \%$ & $59.7 \%$ & $21.3 \%$ \\
\hline Obesity & $30.3 \%$ & $95.2 \%$ & $93.9 \%$ & $39.9 \%$ & $25.6 \%$ \\
\hline Physical inactivity & $17.8 \%$ & $93.0 \%$ & $77.2 \%$ & $22.2 \%$ & $71.1 \%$ \\
\hline Poor oral hygiene & $95.8 \%$ & $73.8 \%$ & $57.6 \%$ & $55.0 \%$ & $12.1 \%$ \\
\hline Postmenopausal & $29.4 \%$ & $40.8 \%$ & $18.7 \%$ & N/A & $81.6 \%$ \\
\hline Race & $48.4 \%$ & $73.3 \%$ & $52.6 \%$ & $22.9 \% *$ & $36.6 \%$ \\
\hline Oral bacteria & $89.5 \%$ & $57.1 \%$ & $31.5 \%$ & $37.0 \%$ & $7.4 \%$ \\
\hline Smoking & $94.8 \%$ & $94.5 \%$ & $55.2 \%$ & $81.9 \%$ & $40.8 \%$ \\
\hline Systemic inflammation & $69.9 \%$ & $79.0 \%$ & $60.4 \%$ & $54.7 \%$ & $25.6 \%$ \\
\hline
\end{tabular}

$\mathrm{CVD}=$ cardiovascular disease; PTB/LBW=preterm birth, low birthweight (adverse pregnancy outcomes); N/A=not applicable *Significantly incorrect answer identification 
and pregnancy complications than about the risk factors for osteoporosis.

Table 3 shows the responding dentists' opinions on the strength of evidence linking periodontal disease to various systemic conditions. Among these dentists, $71.1 \%$ rated the evidence supporting an association between periodontal disease and cardiovascular disease as strong. Similarly, $67.0 \%$ reported feeling that the evidence was strong regarding the association between periodontal disease and diabetes mellitus. Whereas $38.1 \%$ of the respondents rated the evidence as strong for the association between periodontal disease and pregnancy complications, less than $15 \%$ agreed the evidence on the associations of periodontal disease with respiratory disease, osteoporosis, and obesity was strong.

These dentists' comfort and confidence levels concerning management of oral-systemic health in patients are quantified in percentage agreement in Table 4 . The responding dentists were comfortable treating patients who have cardiovascular disease $(86.0 \%)$ or diabetes $(88.7 \%)$ and concomitant periodontal disease. They were less comfortable treating female patients who may be at risk for adverse pregnancy outcomes like preterm delivery and low birthweight (52.4\%). These dentists in general were

Table 3. North Carolina dentists' perceptions regarding strength of evidence linking periodontal disease to various systemic conditions, by number and percentage of respondents to each item

\begin{tabular}{lccccccccc} 
& & \multicolumn{2}{c}{ None } & & Weak & & Moderate & \multicolumn{2}{c}{ Strong } \\
\hline Condition & Respondents & $N$ & Percent & $N$ & Percent & N & Percent & $N$ & Percent \\
\hline Cardiovascular disease & 647 & 0 & 0 & 30 & $4.6 \%$ & 157 & $24.3 \%$ & 460 & $71.1 \%$ \\
Diabetes & 642 & 0 & 0 & 43 & $6.7 \%$ & 169 & $26.3 \%$ & 430 & $67.0 \%$ \\
Pregnancy & 635 & 7 & $1.1 \%$ & 149 & $23.5 \%$ & 237 & $37.3 \%$ & 242 & $38.1 \%$ \\
Respiratory disease & 633 & 45 & $7.1 \%$ & 271 & $42.8 \%$ & 229 & $36.2 \%$ & 88 & $13.9 \%$ \\
Osteoporosis & 630 & 54 & $8.6 \%$ & 302 & $47.9 \%$ & 206 & $32.7 \%$ & 68 & $10.8 \%$ \\
Obesity & 628 & 55 & $8.8 \%$ & 272 & $43.3 \%$ & 235 & $37.4 \%$ & 66 & $10.5 \%$ \\
\hline
\end{tabular}

Table 4. North Carolina dentists' level of agreement with statements about their comfort and confidence levels concerning several areas of oral-systemic health, by percentage of respondents to each item

\begin{tabular}{|c|c|c|c|c|}
\hline Statement & Respondents & $\begin{array}{l}\text { Strongly } \\
\text { Agree/Agree }\end{array}$ & Neutral & $\begin{array}{c}\text { Strongly } \\
\text { Disagree/ } \\
\text { Disagree }\end{array}$ \\
\hline \multicolumn{5}{|l|}{ I feel comfortable asking patients about: } \\
\hline Their alcohol habits. & 647 & $53.5 \%$ & $27.2 \%$ & $19.3 \%$ \\
\hline Their tobacco habits. & 648 & $92.5 \%$ & $5.4 \%$ & $2.1 \%$ \\
\hline \multicolumn{5}{|l|}{ I feel comfortable: } \\
\hline Referring patients who use tobacco to a Quitline. & 641 & $62.1 \%$ & $27.3 \%$ & $10.6 \%$ \\
\hline $\begin{array}{l}\text { Treating patients who may be at risk for adverse pregnancy } \\
\text { outcomes (low birthweight/preterm delivery). }\end{array}$ & 643 & $52.4 \%$ & $27.5 \%$ & $20.1 \%$ \\
\hline $\begin{array}{l}\text { Treating patients who have both cardiovascular disease and } \\
\text { periodontal disease. }\end{array}$ & 645 & $86.0 \%$ & $10.4 \%$ & $3.6 \%$ \\
\hline Treating patients who have both diabetes and periodontal disease. & 645 & $88.7 \%$ & $8.8 \%$ & $2.5 \%$ \\
\hline \multicolumn{5}{|l|}{ I feel confident that I can: } \\
\hline $\begin{array}{l}\text { Counsel patients about the effects of alcohol on their oral-systemic } \\
\text { health. }\end{array}$ & 644 & $48.6 \%$ & $33.2 \%$ & $18.2 \%$ \\
\hline Counsel my patients on how to quit using tobacco. & 644 & $56.2 \%$ & $27.5 \%$ & $16.4 \%$ \\
\hline $\begin{array}{l}\text { Discuss potential risks with pregnant patients who have } \\
\text { periodontal disease. }\end{array}$ & 645 & $85.0 \%$ & $10.9 \%$ & $4.2 \%$ \\
\hline $\begin{array}{l}\text { Discuss potential oral-systemic risks with cardiovascular patients } \\
\text { who also have periodontal disease. }\end{array}$ & 645 & $83.8 \%$ & $13.3 \%$ & $2.9 \%$ \\
\hline $\begin{array}{l}\text { Discuss potential oral-systemic risks to patients with diabetes } \\
\text { who also have periodontal disease. }\end{array}$ & 645 & $88.1 \%$ & $8.5 \%$ & $3.4 \%$ \\
\hline
\end{tabular}


uniformly confident in discussing the oral-systemic risks to periodontally diseased patients with cardiovascular disease or diabetes or who are pregnant (range 83.8-88.1\%). The respondents also reported feeling comfortable asking patients about their tobacco habits $(92.5 \%)$. In contrast, they were less comfortable about referring patients who use tobacco to Quitline (62.1\%) and were less confident about counseling patients to quit using tobacco $(56.2 \%)$. These dentists were least comfortable in asking patients about their alcohol habits (53.5\%) and least confident about counseling patients on the effects of alcohol (48.6\%).

The responding dentists' levels of agreement with other survey items assessing incorporation of oral-systemic health evidence into patient care are shown in Table 5. Of these dentists, 90.5\% agreed that they ask detailed follow-up questions to patients regarding any affirmative answers on medical history forms. Three-quarters agreed that they thoroughly assess the patient's risk for systemic disease as it relates to the oral condition. A comparable proportion $(73.6 \%)$ agreed that they adjust the frequency of dental visits for patients with diabetes, cardiovascular disease, or other conditions due to risks. The majority of responding dentists rated their knowledge of periodontal disease $(82.6 \%)$ and that of their staff members $(75.3 \%)$ as "current," while $90.3 \%$ agreed that they provide "thorough" periodontal therapies to patients in their practices. Although $74.1 \%$ of these dentists encouraged their staff members to incorporate the evidence on oral-systemic disease into their clinical practice and interactions with patients, only $27.9 \%$ were interested in expanding their practices to include the management of patients with complicated medical conditions. A minority $(11.2 \%)$ responded that the evidence relating periodontal disease and systemic disease is not conclusive.

Table 6 lists the responding dentists' opinions on training, collaboration, and patient expectations associated with oral and systemic health. More than $90 \%$ of the respondents agreed that dentists and dental hygienists should be trained to identify risk factors for oral-systemic disease (range 93.4-95.5\%). Almost three-quarters of the respondents agreed that dentists should be trained to actively manage patients with systemic disease. A majority (65.8\%) agreed that dental hygienists should receive comparable training in the management of patients with systemic conditions.

Interestingly, $91.9 \%$ of the respondents agreed that dental and medical professionals should be taught to practice in a more collaborative way during their formal education programs. Regarding patient expectations, $71.6 \%$ of these dentists perceived that patients appreciated their asking questions about systemic health; however, only

Table 5. North Carolina dentists' level of agreement with statements about incorporating oral-systemic evidence into patient care, by percentage of respondents to each item

\begin{tabular}{|c|c|c|c|c|}
\hline Statement & espondents & $\begin{array}{l}\text { Strongly } \\
\text { Agree/Agree }\end{array}$ & Neutral & $\begin{array}{l}\text { Strongly } \\
\text { Disagree/ } \\
\text { Disagree }\end{array}$ \\
\hline $\begin{array}{l}\text { I ask very thorough/detailed follow-up questions to "yes" answers } \\
\text { on the medical history form. }\end{array}$ & 642 & $90.5 \%$ & $8.4 \%$ & $1.1 \%$ \\
\hline $\begin{array}{l}\text { I thoroughly assess the patient's risk for systemic disease as it relates } \\
\text { to his/her oral condition. }\end{array}$ & 643 & $75.9 \%$ & $20.2 \%$ & $3.9 \%$ \\
\hline $\begin{array}{l}\text { I adjust the frequency of dental visits as needed for patients with diabetes, } \\
\text { CVD, or other conditions that might place them at risk for oral-systemic } \\
\text { complications. }\end{array}$ & $\begin{array}{l}\text { S, } 644 \\
\text { C }\end{array}$ & $73.6 \%$ & $20.0 \%$ & $6.4 \%$ \\
\hline My knowledge about periodontal disease is current. & 643 & $82.6 \%$ & $15.1 \%$ & $2.4 \%$ \\
\hline My staff's knowledge about periodontal disease is current. & 640 & $75.3 \%$ & $21.3 \%$ & $3.5 \%$ \\
\hline $\begin{array}{l}\text { I provide thorough periodontal therapies to my patients (scaling and } \\
\text { root planing, etc.). }\end{array}$ & 645 & $90.3 \%$ & $6.2 \%$ & $3.6 \%$ \\
\hline $\begin{array}{l}\text { The evidence relating periodontal disease and systemic disease is not } \\
\text { conclusive. }\end{array}$ & 642 & $11.2 \%$ & $15.6 \%$ & $73.3 \%$ \\
\hline $\begin{array}{l}\text { I encourage my staff members to incorporate evidence about oral- } \\
\text { systemic disease into clinical practice. }\end{array}$ & 648 & $74.1 \%$ & $20.7 \%$ & $5.2 \%$ \\
\hline I am interested in expanding my practice to include the management & 651 & $27.9 \%$ & $40.9 \%$ & $31.2 \%$ \\
\hline
\end{tabular}
of patients with complicated medical conditions. 
$19.8 \%$ reported feeling that patients wanted them to take a more "active role" in the management of systemic health. Among these dentists, 43.4\% reported having experienced an increase in the number of questions from patients on oral-systemic health relationships. When asked about interprofessional collaboration in delivering patient care, only $22.0 \%$ reported feeling that the physicians and nurses in their communities were knowledgeable about oralsystemic connections. A majority of the responding dentists $(63.9 \%)$ reported that medical providers (e.g., physicians and nurses) should be trained to screen patients for periodontal disease, and $73.8 \%$ responded that they were interested in collaborating more with physicians and nurses to improve the interprofessional care of patients.

Bivariate analysis of the data indicated that age, practice type, and setting were statistically significant explanatory variables for some of the dentists' comfort and confidence levels concerning oral and systemic health (Figure 1, Figure 2). In particular, dentists more than 40 years of age more frequently indicated (i.e., strongly agreed) that they were comfortable discussing alcohol $(\mathrm{p}=0.03)$ or tobacco $(p=0.01)$ usage with patients. They were also more comfortable treating patients at risk for adverse pregnancy outcomes $(\mathrm{p}<0.01)$ relative to younger dentists. Solo practitioners more frequently indicated that they were confident in counseling patients on the effects of alcohol on oral-systemic health $(p=0.01)$ and in counseling patients about the potential risks with cardiovascular disease patients $(\mathrm{p}=0.01)$. Significantly more dentists practicing in urban or suburban communities felt confident in counseling patients with diabetes and periodontal disease about oral-systemic risks ( $\mathrm{p}=0.04)$.

Table 6. North Carolina dentists' agreement with statements about training, collaboration, and patient expectations, by percentage of respondents to each item

\begin{tabular}{|c|c|c|c|c|}
\hline Statement & Respondents & $\begin{array}{l}\text { Strongly } \\
\text { Agree/Agree }\end{array}$ & Neutral & $\begin{array}{c}\text { Strongly } \\
\text { Disagree/ } \\
\text { Disagree }\end{array}$ \\
\hline \multicolumn{5}{|l|}{ Training } \\
\hline $\begin{array}{l}\text { Dentists should be trained to identify risk factors for oral- } \\
\text { systemic disease. }\end{array}$ & 643 & $95.5 \%$ & $4.2 \%$ & 0 \\
\hline $\begin{array}{l}\text { Dental hygienists should be trained to identify risk factors for } \\
\text { oral-systemic disease. }\end{array}$ & 641 & $93.4 \%$ & $6.2 \%$ & 0 \\
\hline $\begin{array}{l}\text { Dentists should be trained to actively manage a patient with } \\
\text { systemic disease (e.g., diabetes, respiratory disease, CVD). }\end{array}$ & 647 & $73.6 \%$ & $15.3 \%$ & $3.3 \%$ \\
\hline $\begin{array}{l}\text { Dental hygienists should be trained to actively manage a patient } \\
\text { with systemic disease (e.g., diabetes, respiratory disease, CVD). }\end{array}$ & 647 & $65.8 \%$ & $19.6 \%$ & $5.7 \%$ \\
\hline $\begin{array}{l}\text { During their formal education, dental and medical professionals } \\
\text { should be taught to practice in a more collaborative way. }\end{array}$ & 652 & $91.9 \%$ & $8.0 \%$ & 0 \\
\hline \multicolumn{5}{|l|}{ Collaboration } \\
\hline $\begin{array}{l}\text { Medical providers should be trained to screen patients for } \\
\text { periodontal disease. }\end{array}$ & 644 & $63.9 \%$ & $26.6 \%$ & $0.8 \%$ \\
\hline $\begin{array}{l}\text { Medical colleagues would like for me to take a more active role } \\
\text { in the management of my patients' systemic health issues } \\
\text { (diabetes, respiratory disease, CVD, etc.). }\end{array}$ & 651 & $11.6 \%$ & $49.8 \%$ & $7.2 \%$ \\
\hline $\begin{array}{l}\text { Physicians and nurses in my area are knowledgeable about oral- } \\
\text { systemic connections. }\end{array}$ & 651 & $22.0 \%$ & $45.9 \%$ & $3.8 \%$ \\
\hline $\begin{array}{l}\text { I am interested in collaborating more with physicians and nurses } \\
\text { to improve interprofessional care of patients. }\end{array}$ & 653 & $73.8 \%$ & $22.2 \%$ & $0.3 \%$ \\
\hline \multicolumn{5}{|l|}{ Patient expectations } \\
\hline $\begin{array}{l}\text { My patients would like for me to take a more active role in the } \\
\text { management of their systemic health. }\end{array}$ & 648 & $19.8 \%$ & $50.9 \%$ & $4.0 \%$ \\
\hline $\begin{array}{l}\text { My patients appreciate it when I ask them questions about their } \\
\text { systemic health. }\end{array}$ & 650 & $71.6 \%$ & $25.1 \%$ & 0 \\
\hline $\begin{array}{l}\text { I have experienced an increase in the number of questions patients } \\
\text { ask me about oral-systemic relationships. }\end{array}$ & 650 & $43.4 \%$ & $38.5 \%$ & $1.7 \%$ \\
\hline \multicolumn{5}{|l|}{$\begin{array}{l}\text { CVD }=\text { cardiovascular disease } \\
\text { Note: Percentages may not total } 100 \% \text { due to rounding. }\end{array}$} \\
\hline
\end{tabular}




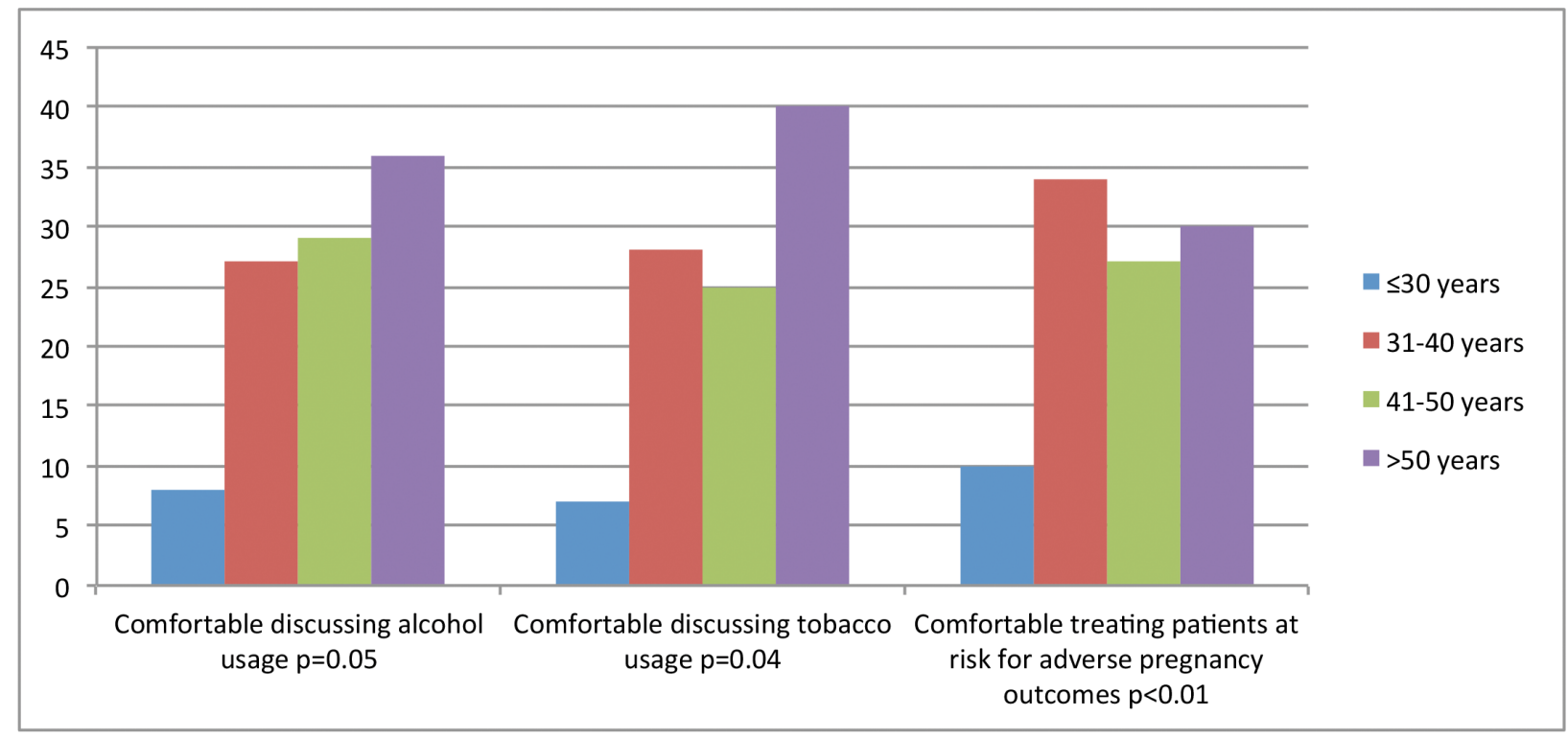

Figure 1. Percentage of respondents who strongly agreed with statements regarding their comfort level with three patient practices, by age category (in years)

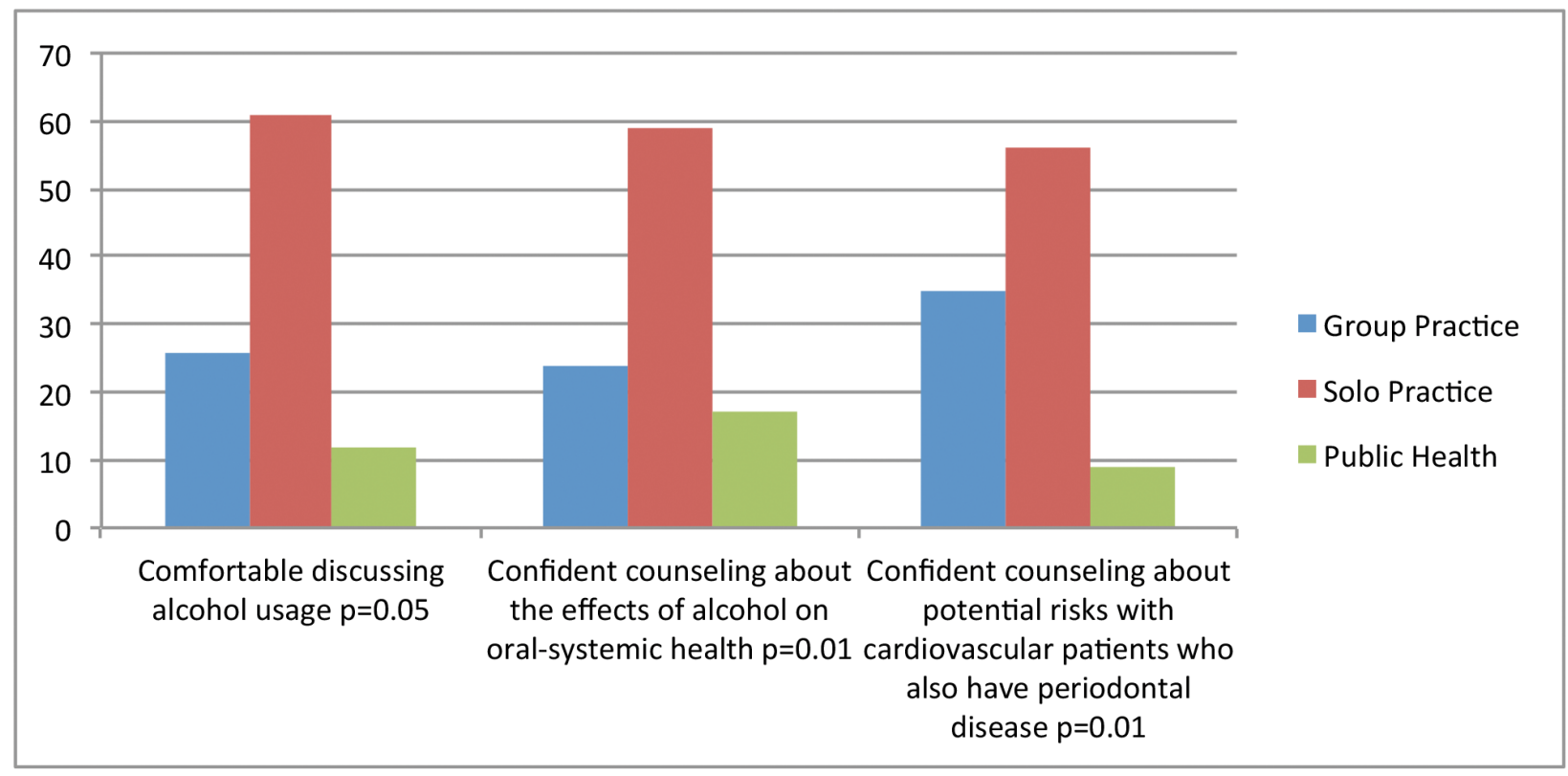

Figure 2. Percentages of respondents who strongly agreed with statements regarding their comfort and confidence level by type of practice 


\section{Discussion}

This is the fourth report of our survey findings on North Carolina dental providers' views and behaviors on oral-systemic health. ${ }^{14-16}$ We have previously reported that most dental hygienists $(\geq 70 \%)$ in the study rated the evidence linking periodontal disease and cardiovascular disease or diabetes mellitus as strong. ${ }^{14}$ The majority of those dental hygienists reported feeling that they should be trained to identify risk factors for oral-systemic disease (94\%) and to actively manage patients with systemic disease (78\%). Similarly, most dental hygienist respondents have reported feeling comfortable discussing systemic health issues with patients and agreed that they have a role in referring patients to a medical doctor or dental specialist. ${ }^{15}$ Meanwhile, when North Carolina dentists were surveyed on practice behaviors and barriers, half of the respondents reported updating medical histories at every visit. ${ }^{16}$ While a high proportion of these dentists $(87.6 \%)$ were likely or extremely likely to refer patients to a medical provider for follow-up of signs and symptoms detected during a dental appointment, smaller proportions were likely or extremely likely to discuss obesity with patients $(21.3 \%)$, refer a patient to a laboratory or physician for glucose testing (34.2\%), or directly screen for diabetes using a point-of-care glucose monitor (7.6\%).

The data from this latest report indicate that a high proportion of these North Carolina dentists appear to be knowledgeable about risk factors for major systemic diseases and that most rated the evidence linking periodontal disease with cardiovascular disease and diabetes as strong. Since the surveyed dentists were exclusively from the state of North Carolina, the generalizability of these findings to other regions or nationally is limited. While the survey collected demographic data including practitioner age and practice setting, it did not collect data on other potential correlates like years since graduation or faculty appointment at a dental school. Nevertheless, a majority of North Carolina dentists in our study reported feeling comfortable treating patients with periodontal disease and concomitant systemic conditions and confident discussing risks with patients affected by systemic conditions. In contrast, they reported feeling less comfortable or were less likely to participate in the active management of patients' systemic conditions to include counseling for risk behaviors, referral for laboratory testing, or in-office diagnostic screening for medical conditions.
Other surveys have sought to document perceived knowledge among dentists regarding chronic systemic conditions and their willingness to manage their patients' overall health as a member of the health care team. A 2002 survey of approximately 100 general dentists from the Northeast U.S. found that most perceived their knowledge about smoking cessation and diabetes management as inadequate..$^{10}$ Only one out of three respondents in that study agreed that colleagues or patients expected them to take a more active role in controlling patients' diabetes. When New Zealand general dentists were surveyed in 2005 using the same questionnaire, they also self-reported low ratings for knowledge of diabetes risk factors, diabetes management and prevention, and management of diabetic emergencies. ${ }^{12}$ In comparing the data from those two studies with ours on North Carolina dentists, we acknowledge that there were differences in study demographics, questionnaires, rating scales, sample sizes, and time of survey. While the North Carolina general dentists surveyed in 2010 perceived that they have an adequate level of knowledge of chronic systemic diseases, they reported a low level of actively participating in the management of their patients' overall health.

A number of recent studies have demonstrated the utility, potential efficacy, and cost-effectiveness of screening patients for medical conditions in the dental setting. Analyzing data from the National Health and Nutrition Survey (NHANES), Glick and Greenberg found that $18 \%$ of the male subjects (ages $40-84$ years) with no reported risk factors for coronary heart disease and who had seen a dentist in a given year but not a physician exhibited a significantly increased ten-year global risk of a coronary heart disease event (e.g., $>10 \%$ risk for myocardial infarction, stroke, or death) based on Framingham risk scores. ${ }^{17}$ When those authors extrapolated the results to the 2000 U.S. census data, they estimated that approximately 332,000 adult males at risk for coronary heart disease events could be identified in the dental setting annually via the application of Framingham-based risk calculation scoring. In a similar analysis of NHANES data, Strauss et al. reported that $93 \%$ of U.S. adults over 20 years of age undiagnosed with diabetes but with moderate to severe periodontal disease have risk factors indicating the importance of diabetes screening. ${ }^{18}$ The investigators determined that $50 \%$ of those persons who had seen a dentist in the previous year could have been screened in the dental office and potentially benefited from early intervention. In two independent cross-sectional studies, the combination 
of deep periodontal pocketing, missing teeth, and an abnormal point-of-care hemoglobin A1c (HbA1c) correctly identified about $90 \%$ of patients with diabetes or pre-diabetes. ${ }^{19,20}$ Lastly, according to one analysis of U.S. population data, an estimated $\$ 42.4$ million to $\$ 102.6$ million in health care spending could be saved annually if medical screenings for diabetes, hypertension, and hypercholesterolemia were routinely performed in dental offices. ${ }^{21}$

In general, both dentists and patients report positive attitudes about screening for medical conditions in the dental setting. One large survey of approximately 2,000 U.S. dentists conducted in 2008 found that the majority thought it was important for dentists to conduct screenings for hypertension $(85.8 \%)$, cardiovascular disease $(76.8 \%)$, diabetes (76.6\%), hepatitis (71.5\%), and human immunodeficiency virus (HIV) infection $(68.8 \%)$. $^{22}$ Those respondents reported being willing to collect oral fluids for salivary diagnostics $(87.7 \%)$ and conduct medical screenings that yield immediate results (83.4\%), but were less willing to collect blood via finger stick (55.9\%). In another study, the majority of patients surveyed were willing to have a dentist conduct screenings for heart disease, hypertension, diabetes, HIV infection, and hepatitis infection (55$89 \%$ ), and most were willing to provide oral fluids or a finger stick blood sample (60-87\%). ${ }^{23}$ In addition, most of those patients reported a higher perception of a dentist's professionalism, knowledge, competence, and compassion $(48-77 \%)$ if the dentist performed medical screenings. A more recent survey of 67 U.S. and Swedish dental offices participating in a dental practice-based research network found that most dentists and staff members perceived random blood glucose testing of patients as useful and worth routine implementation. ${ }^{24}$ More than $80 \%$ of the surveyed patients reported thinking that random blood glucose testing in the dental office was a good idea and easy to withstand. These collective published findings indicate dentists' willingness and patients' acceptance for dentists to play a more active role in patient screening and overall health management.

The data from this latest report on North Carolina dentists' knowledge of and opinions on oral-systemic disease relationships indicate the need for formal instruction on patient risk assessment, diagnostic screening, and risk counseling for systemic conditions in dental education programs. These latest findings also support the implementation and expansion of interprofessional education to enable dentists to play a more active, collaborative role in patients' overall systemic health. Indeed, for improved patient outcomes and cost-effectiveness, such initiatives should span the entire spectrum of dental education to include predoctoral, allied, advanced, and continuing dental education. In support of this point, more than $90 \%$ of the North Carolina dentists in our study agreed that predoctoral dental education programs should include the identification of risk factors for oral-systemic diseases, and approximately $75 \%$ agreed that dentists should be trained to actively manage patients with systemic disease.

Similarly, more than $90 \%$ of the dentists in our study agreed that dentists and physicians should be taught to practice in a more collaborative way with interprofessional curricular initiatives. These survey findings support recent revisions in the educational standards to include interprofessional training as part of predoctoral dental and medical education programs. According to the Commission on Dental Accreditation (CODA) Standard 2-19 (implemented in July 2013), "Graduates must be competent in communicating and collaborating with other members of the health care team to facilitate the provision of health care." team include physicians, nurses, pharmacists, physician assistants, and social workers (to name a few), all focused on patient outcomes within that patient's support environment. Similarly, accreditation Standard 6.7 of the Liaison Committee on Medical Education requires that "The faculty of a medical school ensure that medical students have opportunities to learn in academic environments that permit interactions with students enrolled in other health professions, graduate and professional degree programs, and in clinical environments that provide opportunities for interaction with physicians in graduate medical education programs and in continuing medical education programs."

Interprofessional education on oral and systemic health will enhance collaboration among health professionals in delivering patient care and improving patient outcomes. A 2009 editors' consensus report published in the American Journal of Cardiology and the Journal of Periodontology concluded: "because untreated or inadequately controlled moderate to severe periodontitis increases the systemic inflammatory burden, periodontitis may independently increase the risk for cardiovascular disease." $", 7$ The consensus report also recommended that dentists (periodontists) and physicians managing patients with cardiovascular disease "should closely collaborate to optimize cardiovascular risk reduction 
and periodontal care." The data from our study indicate that most dentists practicing in North Carolina are willing to collaborate more with physicians, nurses, and other health professionals to improve the overall well-being of patients.

\section{Conclusion}

The data from this study suggest that North Carolina dentists are knowledgeable about oralsystemic health associations but have mixed comfort levels translating the evidence into clinical practice. However, they generally support formal interprofessional education and practice to improve patient care outcomes.

\section{Acknowledgments}

Funding for this research was provided by Johnson \& Johnson Healthcare Products, a division of McNeil-PPC, Inc.

\section{Disclosure}

One of the authors served on the Scientific Advisory Board of Johnson \& Johnson, which sponsored this study.

\section{REFERENCES}

1. Oral health in America: a report of the surgeon generalexecutive summary. Rockville, MD: U.S. Department of Health and Human Services, National Institute of Dental and Craniofacial Research, National Institutes of Health, 2000.

2. Bahekar AA, Singh S, Saha S, et al. The prevalence and incidence of coronary heart disease is significantly increased in periodontitis: a meta-analysis. Am Heart J 2007; 154(5):830-7.

3. Sfyroeras GS, Roussas N, Saleptsis VG, et al. Association between periodontal disease and stroke. J Vasc Surg 2012;55(4):1178-84.

4. Borgnakke WS, Ylöstalo PV, Taylor GW, Genco RJ. Effect of periodontal disease on diabetes: systematic review of epidemiologic observational evidence. J Clin Periodontol 2013;40(Suppl 14):S135-52.

5. Xiong X, Buekens P, Fraser WD, et al. Periodontal disease and adverse pregnancy outcomes: a systematic review. $\mathrm{Br}$ J Obstet Gynecol 2006;113(2):135-43.

6. Friedewald VE, Kornman KS, Beck JD, et al. The American Journal of Cardiology and Journal of Periodontology editors' consensus: periodontitis and atherosclerotic cardiovascular disease. Am J Cardiol 2009;104(1):59-68.

7. Friedewald VE, Kornman KS, Beck JD, et al. The American Journal of Cardiology and Journal of Periodontology editors' consensus: periodontitis and atherosclerotic cardiovascular disease. J Periodontol 2009;80(7):1021-32.
8. Commission on Dental Accreditation. Accreditation standards for predoctoral dental education programs. 2010. At: www.ada.org/ /media/CODA/Files/predoc_2013.ashx. Accessed 2 July 2014.

9. Liaison Committee on Medical Education. Functions and structure of a medical school: standards for accreditation of medical education programs leading to the MD degree. 2014. At: www.lcme.org/publications/2015-16-functionsand-structure-with-appendix.pdf. Accessed 2 July 2014.

10. Kunzel C, Lalla E, Albert DA, et al. On the primary care frontlines: the role of the general practitioner in smokingcessation activities and diabetes management. J Am Dent Assoc 2005;136(8):1144-53.

11. Kunzel C, Lalla E, Lamster I. Dentists' management of the diabetic patient: contrasting generalists and specialists. Am J Public Health 2007;97(4):725-30.

12. Forbes K, Thomson WM, Kunzel C, et al. Management of patients with diabetes by general dentists in New Zealand. J Periodontol 2008;79(8):1401-8.

13. Salant P, Dillman DA. How to conduct your own survey. New York: Wiley, 1994.

14. Bell KP, Phillips C, Paquette DW, et al. Dental hygienists' knowledge and opinions of oral-systemic connections: implications for education. J Dent Educ 2012;76(6): 682-94.

15. Bell KP, Phillips C, Paquette DW, et al. Incorporating oralsystemic evidence into patient care: practice behaviors and barriers of North Carolina dental hygienists. J Dent Hyg 2011;85(2):99-113.

16. Wilder RS, Bell KP, Paquette DW, et al. Dentists' practice behaviors and barriers regarding oral-systemic evidence: implications for education. J Dent Educ 2014;78(9): 1252-62.

17. Glick M, Greenberg BL. The potential role of dentists in identifying patients' risk of experiencing coronary heart disease events. J Am Dent Assoc 2005;136(11):1541-6.

18. Strauss SM, Russell S, Wheeler A, et al. The dental office visit as a potential opportunity for diabetes screening: an analysis using NHANES 2003-04 data. J Public Health Dent 2010;70(2):156-62.

19. Lalla E, Kunzel C, Burkett S, et al. Identification of unrecognized diabetes and pre-diabetes in a dental setting. J Dent Res 2011;90(7):855-60.

20. Lalla E, Cheng B, Kunzel C, et al. Dental findings and identification of undiagnosed hyperglycemia. J Dent Res 2013;92(10):888-92.

21. Nasseh K, Greenberg B, Vujicic M, Glick M. The effect of chairside chronic disease screenings by oral health professionals on health care costs. Am J Public Health 2014; 104(4):744-50.

22. Greenberg BL, Glick M, Frantsve-Hawley J, Kantor ML. Dentists' attitudes toward chairside screening for medical conditions. J Am Dent Assoc 2010;141(1):52-62.

23. Greenberg BL, Kantor ML, Jiang SS, Glick M. Patients' attitudes toward screening for medical conditions in a dental setting. J Public Health Dent 2012;72(1):28-35.

24. Barasch A, Safford MM, Qvist V, et al. Random blood glucose testing in dental practice: a community-based feasibility study from the dental practice-based research network. J Am Dent Assoc 2012;143(3):262-9. 